\title{
ON WELFARE AND REVENUE EFFECTS OF INDIRECT TAX HARMONIZATION
}

\author{
Miguel-Angel LOPEZ-GARCIA (*) \\ Departamento de Economia Aplicada \\ Universidad Autonoma de Barcelona \\ 08193 Bellaterra, Barcelona, Spain \\ Telf.: (3) 5811229 \\ Fax: (3) 5812292
}

September 1997

\begin{abstract}
This paper discusses whether some of the propositions concerning indirect tax harmonization that have been derived in models where tax revenue is returned to the consumers as a lump-sum transfer can also be extended to the more relevant situations in which governments levy taxes to finance the purchase of goods and services. Using a twocountry model, it is argued that a family of indirect tax harmonization policies, expressed as a multilateral movement of domestic taxes towards an appropriately designed ôaverageö tax structure, can be characterized as potentially welfare improving.
\end{abstract}

(*) Research support from the Fundacion Banco Bilbao Vizcaya (BBV, Spain) is gratefully acknowledged 


\section{Introduction}

Some of the contributions in the recent literature on multilateral tax reform have focused on the welfare effects of indirect tax harmonization policies [Keen $(1987,1989)$, Turunen-Red and Woodland (1991), Keen and Lahiri (1993), Kanbur and Keen (1993), Lopez-Garcia (1996)]. The models underlying these contributions usually assume that tax revenue is returned to the individuals as a lump-sum transfer, and the budgetary and distributional implications of harmonization are sidestepped. As a consequence, this assumption has been pointed out as one of the main limitations of the analysis in its application as a support to the harmonization efforts that have been carried out in the European Union. Subsequent papers by Delipalla (1997), Lockwood (1997) and Lahiri and Raimondos (1997) have discussed the effects of KeenÆs rules as well as other harmonization rules in the presence of local public goods provision in different frameworks. Although there are important differences in their frameworks, one can advance that there may be a welfare case for tax harmonization even when the governments use tax revenue to finance the provision of public goods.

The purpose of this paper is to discuss whether some of the propositions concerning indirect tax harmonization that have been derived in models where tax revenue is returned to the consumers as a lump-sum transfer can also be extended to the more relevant situations in which the governments levy taxes to finance the purchase of goods and services. In a sense, the model is midway between KeenÆs and those referred to in the previous paragraph. It is simpler in that optimal public good provision is not explicity taken into account, and, as in Delipalla (1997), international transfers both between individuals and between governments are considered as feasible.

Using a two-country model, it is argued that a familiy of indirect tax harmonization policies, consisting of a non-uniform proportional convergence towards an appropriately designed ôaverageö tax structure, can be characterized as potentially welfare improving. This family includes as a particular case that analyzed in Keen $(1987,1989)$, i.e., a uniform movement of domestic taxes towards a target vector. It is shown that, provided that the welfare of the foreing countryÆs consumer is kept constant with the aid of an international transfer between consumers, the addition of the income equivalent of the home country Es consumer welfare change and the variations in both countriesÆ tax revenue is strictly positive.

The structure of the paper is as follows. The framework and the assumptions of the model are set up in section 1. Section 2 discusses the tax harmonization rule and its potential 
welfare effects, providing a graphical representation. Section 3 concludes with some final remarks.

\section{The model}

The framework for the analysis is a standard model of international trade in which two countries, ôhomeö and ôabroadö, trade in $N+1$ commodities, indexed as $0,1, \ldots N$. Home (foreign) countryÆs variables are represented by lower (upper) case letters. There is a single consumer in each country, characterized by the expenditure functions $e=e\left(q_{0}, q, u\right)$ and $E=$ $E\left(Q_{0}, Q, U\right)$, where $q_{0}\left(Q_{0}\right), q(Q)$ and $u(U)$ denote the consumer prices and utility level in the home (foreing) country. Thus, the compensated demand functions for the $N+1$ commodities are $e_{0}\left(q_{0}, q, u\right)$ and $e_{q}\left(q_{0}, q, u\right)$ for the home country and $E_{0}\left(Q_{0}, Q, U\right)$ and $\left.E_{Q} Q_{0}, Q, U\right)$ for the foreign one, where the subscripts denote partial derivatives. On the production side it is assumed that there is only one representative firm in each country, whose behaviour can be resumed in the profit functions $\pi=\pi\left(p_{0}, p\right)$ and $\Pi=\Pi\left(P_{0}, P\right)$, where $p_{0}\left(P_{0}\right)$ and $p(P)$ are producer prices in each country. The supply functions can therefore be written as $\pi_{0}\left(p_{0}, p\right)$ and $\pi_{p}\left(p_{0}, p\right)$ for the home country and $\Pi_{0}\left(P_{0}, P\right)$ and $\Pi_{P}\left(P_{0}, P\right)$ for the foreign one.

The government in each country has a revenue requirement expressed in units of the $N+1$ commodities, $g_{0}\left(G_{0}\right)$ and $g(G)$. In order to avoid the complexities associated with the optimal provision of public goods, these government demands are not included in the consumerÆs preferences. The fiscal instruments are consumption taxes, expressed in specific terms, to $\left(T_{0}\right)$ and $t(\mathrm{~T})$, as well as taxes on pure profits, levied at rates $\phi$ and $\Phi$ in each country. The only distortions are due to consumption taxes, which are imposed on a destination basis, so that commodities are taxed at the rates prevailing in the country in which they are consumed, this being the country which collects the tax revenue. As for normalization, commodity 0 is taken to be the numeraire and the untaxed good, so that $t_{0}=T_{0}=0$ and $q_{0}=Q_{0}=p_{0}=P_{0}=1$. This entails a loss of generalization unless profits can be taxed away (i.e., unless $\phi=\Phi=1$ ), but this does not seem to represent a problem in the present context.

Ignoring transport costs and normalizing the exchange rate to unity, arbitrage will imply that producer prices in each country are the same, i.e., $p=P$, so that the relationship between consumer prices for the non-numeraire commodities in each country and world producer prices can be stated as $q=p+t$ and $Q=p+T$. Therefore, the market-clearing conditions for the $N+1$ commodities can be expressed as:

$$
e_{0}(1, p+t, u)+E_{0}(1, p+T, U)+g_{0}+G_{0}=\pi_{0}(1, p)+\Pi_{0}(1, p)
$$

$$
\left.e_{q}(1, p+t, u)+E_{Q} 1, p+T, U\right)+g+G=\pi_{p}(1, p)+\Pi_{p}(1, p)
$$


It is assumed, as in Delipalla (1997), that both international transfers between individuals and between governments are feasible. If $z_{0}$ represents a lump-sum transfer, measured in terms of commodity 0 , from the home countryÆs consumer to the foreign one, whose purpose is to maintain the welfare of the latter unchanged after a multilateral reform of commodity taxation, the consumerÆs budget constraints become:

$$
\begin{aligned}
& e(1, p+t, u)=(1-\phi) \pi(1, p)-z_{0} \\
& E(1, p+T, U)=(1-\Phi) \Pi(1, p)+z_{0}
\end{aligned}
$$

On the other hand, the feasibility of lump-sum transfers between governments is tantamount to the existence of a ôsupranationalö government, whose demands are $\left(g_{0}+G_{0}\right)$ and $(g+G)$, which obtains all the revenue from taxing commodities and profits. Using the sign ' to denote transposition, its budget constraint becomes:

$$
\left.p^{\prime}(g+G)+\left(g_{0}+G_{0}\right)=t^{\prime} e_{q}(1, p+t, u)+T^{\prime} E_{Q} 1, p+T, U\right)+\phi \pi_{p}(1, p)+\Phi \Pi_{p}(1, p)
$$

If, by WalrasÆ law, we drop the market-clearing condition for commodity 0 , the system composed of [2], [3], [4] and the second expression in [1] provides $N+3$ equations with $N+3$ variables, i.e., $N$ world producer prices, $p$, the home country Æs consumer utility level, $u$, the international transfer between consumers, $z_{0}$, and the supranational governmentÆs consumption of the numeraire, $\left(g_{0}+G_{0}\right)$, for given values of the foreign countryÆs consumer utility, $U$, the tax rates in each country, both on commodities, $t$ and $T$, and on pure profits, $\phi$ and $\Phi$, as well as each government $Æ s$ requeriment in terms of the non-numeraire commodities, $g$ and $G$. Notice that since $g$ and $G$ are assumed to be constant, the effect of a certain policy on the ôsupranationalö government can be captured by the impact on $\left(g_{0}+G_{0}\right)$.

We can now consider a multilateral reform of commodity taxation, $\{d t, d T\}$, coupled with whatever change in the transfer between consumers, $d z_{0}$, required to hold the foreing consumerÆs utility $U$ constant, and compute the effects both in terms of the home countryÆs utility, $d u$, and of the supranational government availability of the numeraire, $d\left(g_{0}+G_{0}\right)$. For the sake of simplicity we will assume, as in Keen (1989), Delipalla (1997) and Lahiri and Raimondos (1997), that there are no income effects for the $N$ taxed commodities, i.e., that $e_{q u}=E_{Q U}=0_{N}$ (where $0_{N}$ is the $N$-vector of zeroes), so that all income effects are through the untaxed numeraire. Then we have:

$$
e_{L} d u-\left[g+G-\phi \pi_{p}-\Phi \Pi_{p}\right]^{\prime} d p=-\left[e_{q}^{\prime} d t+E_{Q} d T\right]
$$

[6]

$d\left(g_{0}+G_{0}\right)+\left[g+G-\Phi \pi_{p}-\Phi \prod_{p}-e_{q q}-E_{Q Q}\right]^{\prime} d p=\left[e_{q}+e_{q \phi]^{\prime}} d t+\left[E_{Q}+E_{Q Q}\right]^{\prime} d T\right.$ 
where $\Lambda=e_{q q^{+}} E_{Q Q^{-}} \pi_{p p^{-}} \Pi_{p p}$ is the matrix of the derivatives of the compensated world excess demands for the non-numeraire goods with respect to the non-numeraire prices. From the standard properties $\Lambda$ is negative semi-definite, but we make the standard assumption that there is enough substitutability in demand or production between the numeraire good and the other goods to ensure that $\Lambda$ is negative definite [Dixit and Norman (1980, ch. 5)].

\section{Welfare and revenue effects of tax harmonization}

The notion of harmonization is usually taken to mean making the tax systems more ôuniformö. This entails both a process of convergence towards a common target and the suggestion of determining this target as some kind of ôaverageö of the existing tax structures. Clearly, the reform described as:

$$
d t=\alpha \beta[H-t] \quad d T=\alpha \mathrm{B}[H-T]
$$

where $\alpha$ is a small positive scalar, and $\beta$ and B are arbitrary positive numbers, fulfills the first of the above-mentioned conditions. In effect, since the ôsizeö of the reform is $\alpha \beta$ and $\alpha B$ in each country, [8] characterizes a program of domestic tax reforms in both countries involving a non-uniform proportional convergence of $t$ and $T$ towards a certain common structure $H$.

Concerning the choice of the target vector $H$ as some kind of ôaverageö, the proposition to be discussed below refers to the process of convergence towards a target that depends on the initial tax structures, $t$ and $T$, the local demand responses in each country, $e_{q c}$ and $E_{Q C}$, and the parameters $\beta$ and $\mathrm{B}$. More precisely, the target vector is given by:

$$
H=\left[\beta e_{q q^{+}} \mathrm{B} E_{Q Q^{-1}}\left[\beta e_{q q}+\mathrm{B} E_{Q Q^{\top}}\right]\right.
$$

The interpretation of [9] becomes clearer when it is rewritten as a matrix weighted average of the tax structures in the two countries:

$$
H=\Omega t+\left[I_{N}-\Omega\right] T
$$

where the ôweightsö are $\Omega=\left[\beta e_{q q^{+}} \mathrm{B} E_{Q d^{-1}} \beta e_{q c}\right.$ and $\left[I_{N^{-}} \Omega\right]=\left[\beta e_{q q^{+}} \mathrm{B} E_{Q \phi^{-1}}{ }^{-1} B E_{Q C}\right.$ (and $I_{\Lambda}$ is the identity matrix of order $\left.N\right)$. When the local demand responses are identical at the starting position, $e_{q q}=E_{Q c}$, we have $H=\omega t+(1-\omega) T$ with $\omega=\beta /\left(\beta_{+} B\right)$ and $(1-\omega)=B /(\beta+B)$, i.e., a convex combination of $t$ and $T$. On the other hand, when there are no cross effects in consumption, i.e., when $e_{q c}$ and $E_{Q C}$ are diagonal matrices whose elements $e_{i i}$ and $E_{i i}$ on the 
principal diagonal are negative, $H$ is also a weighted average of $t_{i}$ and $T_{i}, H_{i}=\omega_{i} t_{i}+\left(1-\omega_{i}\right) T_{i}$, where the weights are $\omega_{i}=\beta_{e i i} /\left(\beta_{e i i}+\mathrm{B} E_{i i}\right)$ and $\left(1-\omega_{i}\right)=\mathrm{B} E_{i i} /\left(\beta_{e i i}+\mathrm{B} E_{i i}\right)$.

Notice that [8]-[10] include, as a particular case, that analyzed by Keen (1987,1989), i.e., a uniform proportional convergence of all tax rates towards a common structure which depends on the initial tax structures and local demand responses. In effect, when $\beta=\mathrm{B}=1$, [8] becomes $d t=\alpha[H-t]$ and $d T=\alpha[H-T]$, [9] changes in an obvious way, and [10] can be written as $H=\Sigma t+\left[I_{N}-\Sigma\right] T$, where now the ôweightsö are $\Sigma=\left[e_{q q^{+}} E_{Q d^{-1}} e_{q c}\right.$ and $\left[I_{N}-\Sigma\right]=\left[e_{q q^{+}} E_{Q d^{-1}} E_{Q c}\right.$. It may be noted, incidentally, that Keen $(1989$, p. 7$)$ himself posits the program of harmonizing reforms in a non-uniform way very similar to [8], but he ends up focusing on the uniform case. He discusses the welfare properties of this reform in a model where the tax revenue is returned to the consumers as a lump-sum transfer and no attention is paid to the effects associated with the governments having revenue requeriments or providing public goods. In particular, he shows that under ônormalö circumstances, the reform generates a potential Pareto improvement provided that it is supplemented with the appropriate international transfer (between consumers). Furthermore, when the starting point is a Nash equilibrium, there are ôexceptionalö situations under which the reform is also actually Pareto improving, so that each country(Æs consumer) benefits without any need for an international compensation.

In the present context, the Nash equilibrium can be described as the result of each government adopting the ôautonomous non-coordinated tax policyö analyzed in Rose (1985). In other words, each country sets its tax structure to maximize its own welfare under the assumption that the other one will not change its behaviour. Solving the optimal tax problem, the Nash-equilibrium tax structures in each country, $t_{N}$ and $T_{\Lambda}$, verify:

$$
e_{q d N}=-\theta e_{q}+\theta(1-\phi) e_{q \Phi}\left[\pi_{p p}+\Pi_{p p}\right]^{-1} \pi_{p}+e_{q}\left[\pi_{p p}+\Pi_{p p}\right]^{-1}\left[e_{q}+g-\pi_{p}\right]
$$

$$
\left.\left.E_{Q Q^{\top} N}=-\Theta E_{Q+} \Theta(1-\Phi) E_{Q} \oint \pi_{p p}+\Pi_{p p}\right]^{-1} \Pi_{p}+E_{Q} \oint \pi_{p p}+\Pi_{p p}\right]^{-1}\left[E_{Q}+G-\Pi_{p}\right]
$$

where $\theta$ and $\Theta$ are, respectively, the relative marginal excess burden for the home and foreign country. ${ }^{(1)}$ Notice that the ôspeedö of the adjustment depends on $\beta$ and $B$, and, if desired, it may have an immediate interpretation in terms of $\theta$ and $\Theta$. In effect, if we take $\beta=\theta$ and $\mathrm{B}=\Theta$, then the country with the highest relative marginal excess burden would approach the target given by $H$ more ôquicklyö.

The first step is to note that [8]-[10] imply that the following holds:

$$
e_{q \phi} d t+E_{Q Q d T}=0_{\Lambda}
$$


whose substitution into [7] implies that $d p=0_{\Lambda}$. In words, given the assumption that the income effects for the non-numeraire commodities are zero, world producer prices would remain unchanged after the reform. Under these conditions, [5] and [6] change in an obvious way, and adding them we find:

$$
e_{L} d u+d\left(g_{0}+G_{0}\right)=t^{\prime} e_{q} \phi t+T^{\prime} E_{Q Q 1} T
$$

Notice that [13] can be interpreted as implicitly characterizing the contours of a ôsocial welfare functionö whose arguments are $u$ and $\left(g_{0}+G_{0}\right)$. On the one hand, $e_{l} d u$ is the incomeequivalent of the home countryÆs consumer utility variation, and, on the other one, $d\left(g_{0}+G_{0}\right)$ provides a measure of the impact of the reform on the supranational government Es revenue. In a sense, [21] can be said that encompasses the welfare and revenue effects of the reform. Now we have:

Proposition: Starting from any initial position where $t \quad T$, the harmonizing reform [8][10], entailing a non-uniform proportional convergence of all domestic tax structures towards a target vector which depends on initial taxes, local demand responses, and some (positive) scalars $\beta$ and $\mathrm{B}$, can be said to be welfare-improving in the sense that $e_{L} d u+d\left(g_{0}+G_{0}\right)>0$. Furthermore, if the starting point is a Nash-equilibrium, the choice of $\beta$ and $\mathrm{B}$ is independent from the relative marginal excess burdens in each country, $\theta$ and $\Theta$.

In other words, provided that the welfare of the foreing countryÆs consumer is kept constant with an international transfer between consumers, the addition of the income-equivalent of the home countryÆs consumer welfare change and the variations in both countriesÆ revenue arising from the harmonizing reform [8]-[10] is strictly positive.

Proof: Using [12], the right hand side of [13] can be rewritten as:

$$
t^{\prime} e_{q q} d t+T^{\prime} E_{Q Q} d T=-\alpha[T-t] ' B E_{Q Q} \Omega[T-t]>0
$$

where the positivity follows from the fact that the matrix $\left.\mathrm{B} E_{Q Q} \Omega=\mathrm{B} E_{Q} \oint \beta e_{q q^{+}} \mathrm{B} E_{Q}\right]^{-1} \beta e_{q q}=\left[(1 / \beta) e_{q q}^{-1}+(1 / \mathrm{B}) E_{Q}^{-1}\right]^{-1}$ is negative definite.

The essence of the result is not different from that in Keen $(1987,1989)$. When income effects are assumed away, [12] assures that world producer prices remain unchanged. In turn, this implies that world supply, $\pi_{p}+\Pi_{p}$, will not change, as neither will world demand, $e_{q}+E_{Q}+g+G$. With $g$ and $G$ fixed, the only effect effect of the harmonizng reform is a ôreallocationö of consumption between the consumers of both countries which translates into an increased value of $e_{L} d u+d\left(g_{0}+G_{0}\right)$. It is important to emphasize the extent of the 
proposition, since it only says that $e_{L} d u$ and/or $d\left(g_{0}+G_{0}\right)$ will be positive. Put another way, both $u$ and $\left(g_{0}+G_{0}\right)$ may be higher, but this does not exclude a situation where the home countryÆs consumerÆs welfare is greater (lower) and aggregate revenue has fallen (grown). It may even be the case that there is no change in the supranational government tax revenue, so that the only effect of the reform is to generate a welfare gain to the home countryÆs consumer. Actually, this would be the analogue, in the present model, of Proposition 2 in Delipalla (1997). ${ }^{(2)}$

The situation depicted in figure 1 illustrates the case where $N=1$. It shows the (private plus government) demand schedules of two countries for some commodity, e $e)$.$+g and$ $E$ Q.) $+G$. Income effects are assumed away and $g$ and $G$ are fixed, so that all income and revenue effects are through the (untaxed) numeraire. The supply side is not explicitly introduced, as the reforms under examination entail that the world producer price $p$ remains unchanged. Given the destination-based taxes $t$ and $T$, consumer prices in each country are $q=p+t$ and $Q=p+T$, and the standard measures of excess burden in each of them can be represented as the triangles $A B C$ and $D E F$ respectively. Since the harmonizing reform [8]-[10] does not generate any change in aggregate production, it will not change aggregate consumption either. As a consequence, the new consumer prices in each country, $p+(t+t)$ and $p+(T+T)$, associated with a reform implying $|t|>|T|$, give rise to changes in each countryÆs demand that verify $\quad x=-\quad X$, where $x$ and $X$ denote private consumption. Under these conditions, the reduction in excess burden in the high tax country, $B C H G$, is greater than the increase in excess burden in the low tax country, IJFE. There is, therefore, an aggregate welfare gain measured by the amount $B C H G-I J F E$.

\section{Concluding comments}

This paper has discussed some questions dealing with the welfare and revenue effects of a specific family of indirect tax harmonizing reforms. It has been argued that the property of potential Pareto superiority of these reforms that has been extensively discussed in models where the tax revenue is returned to the consumers as a lump-sum transfer may, in a sense, be extended to a setting where the government uses its revenue to the purchase of commodities. The results, however, hinge on a number of restrictive assumptions, some of them common in the literature dealing with tax harmonizing policies. That of the feasibility of transfers between consumers in the two countries seems particularly unrealistic. In any case, the real issue to be addressed is whether Pareto improvements can occur as a result of tax harmonization in a context where the governments have given public goods commitments that have to be totally financed by indirect taxation. It seemms fair to say that more research on this subject is 
warranted, but it may well be the case, as pointed out by Turunen-Red and Woodland (1991, p. 181-2) that ôsimple proposals that are Pareto improving might not exist.ö

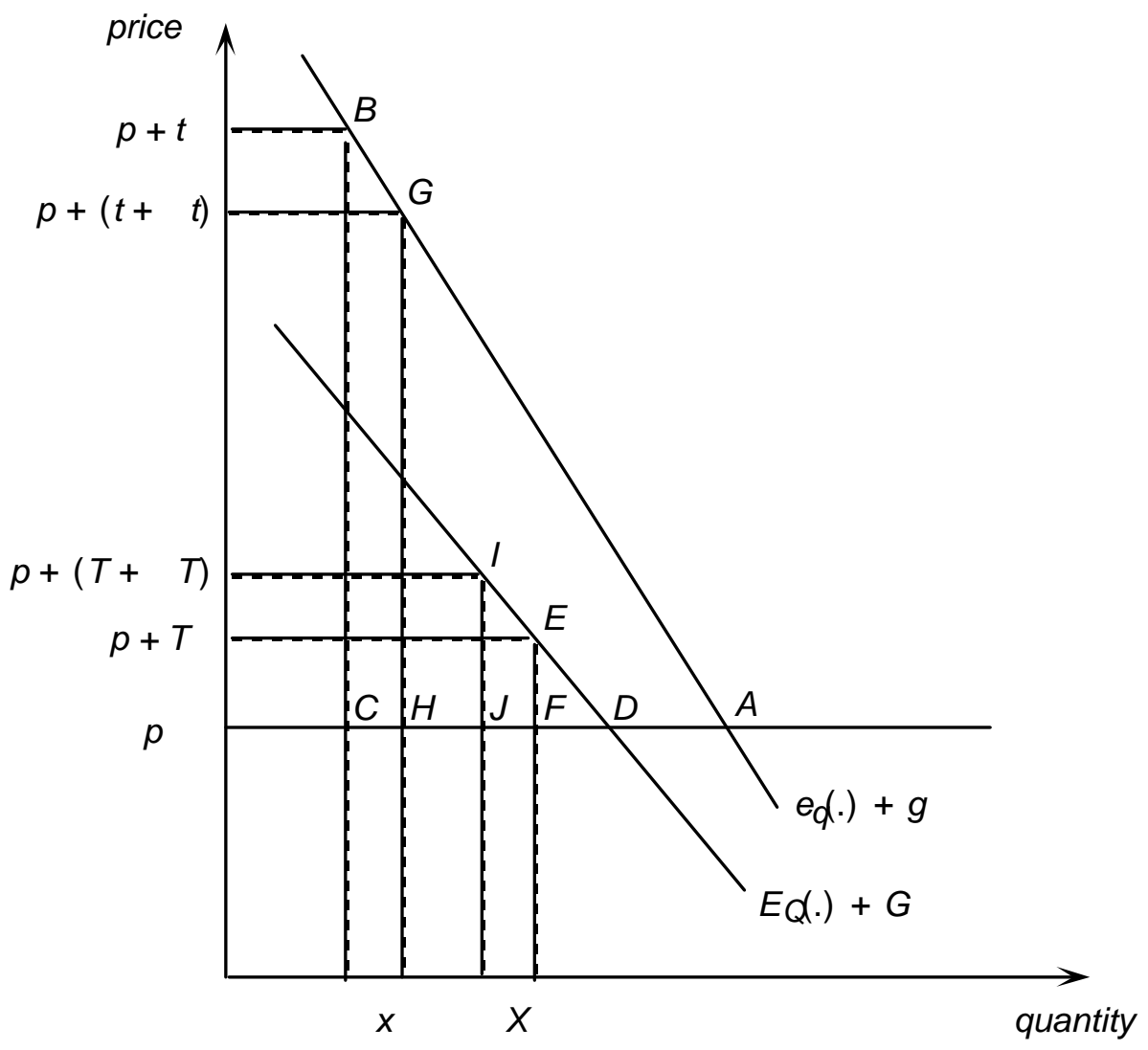

Figure 1: A partial equilibrium illustration of indirect tax harmonization 


\section{Notes}

(1) Our model is simpler than that analyzed in Rose (1985), since both the interdependence with the ôrest of the worldö and some institutional features related to the ôsupranationalö government are excluded. Focusing on the behaviour of the home country, and adopting the so-called expenditure function approach [Dixit and Munk (1977), Munk (1978)], the control variables are $q$ and $u$. Producer prices are determined endogenously via the marketclearing conditions for the non-numerarire commodities, and the tax vector then follows from substraction. The maximization problem to be solved by the home country involves maximizing $u$ subject to the consumerÆs budget constraint, $e(1, p+t, u)=(1-\phi) \pi(1, p)$, and the govermentÆs budget constraint, $p^{\prime} g+g_{0}=(q-p)^{\prime} e_{o}(1, q, u)+\phi \pi(1, p)$. Denoting as $\mu$ and $\gamma$ the corresponding Lagrange multipliers, the first-order conditions allow one to write:

$$
e_{q \Phi N}=-\frac{(\gamma-\mu)}{\gamma} e_{q}+\frac{(\gamma-\mu)}{\gamma}(1-\phi)(\partial p / \partial q)^{\prime} \pi_{p}+(\partial p / \partial q)^{\prime}\left[e_{q}+g-\pi_{p}\right]
$$

where $(\gamma-\mu) / \gamma$ is the relative marginal excess burden from distortionary taxation in the home country, and $(\partial p / \partial q)^{\prime} \pi_{p}=\partial \pi / \partial q$ captures the impact of a marginal change of $q$ on the home countryÆs pure profits. On the other hand, since the second expression in [1] can be written as $p=p(q, Q, u, U, g, G)$, it is immediate to show that $\left(\partial_{p} / \partial_{q}\right)=\left[\pi_{p p}+\Pi_{p p}\right]^{-1}$ eqc, from which the first expression in [11] follows in a direct way.

(2) Delipalla (1997) focus on KeenÆs rule (i.e., [8]-[10] with $\beta=B=1$ ) and calls ôa reform æconditionally revenue neutral $Æ$ if it is revenue neutral at constant $p[$,$] that is, for the$ world as a whole, $\left[e_{q}^{\prime}+t^{\prime} e_{q d} d t+\left[E_{Q}+T^{\prime} E_{Q d} d T=0 \ddot{~}\right.\right.$ (p. 458). In terms of the present model, this condition implies $d\left(g_{0}+G_{0}\right)=0$, i.e., there is no effect on aggregate revenue and $d u$ is positive. We can obtain further insight about this point focusing on the special case where local demand responses are the same, $e_{q q}=E_{Q c}$, thus implying that $H=(1 / 2)(t+T)$. Under these circumstances, the ôconditional revenue neutralityö condition for the world as a whole requires that the following expression be zero:

$$
\left.\left[e_{q}+e_{q \Phi}\right] ' d t+\left[E_{Q}+E_{Q Q T}\right]{ }^{\prime} d T=\frac{\alpha}{2}[T-t]\right]^{\prime}\left[e_{q}-E_{Q}+\alpha t^{\prime} e_{q q} T^{-} \frac{\alpha}{2} ; t^{\prime} e_{q d}+T^{\prime} e_{q q} T^{\prime}\right.
$$

Since the only terms that are unambiguously negative are $t^{\prime} e_{q d}$ and $T^{\prime} e_{q T^{T}}$, this expression will be zero only by chance. If this is the outcome in the simple and relatively tractable case where $e_{q q}=E_{Q c}$, we can only expect that this condition will become more dificult to be fulfilled in more general settings. 


\section{References}

Delipalla, S. (1997), ôCommodity Tax Harmonisation and Public Goodsö, Journal of Public Economics, Vol. 63, pp. 447-466.

Dixit, A.K. and K.J. Munk (1977), ôWelfare Effects of Tax and Price Changes: A Correctionö, Journal of Public Economics, Vol. 8, pp. 103-107.

Dixit, A.K. and V. Norman (1980), Theory of International Trade, Cambridge University Press, Cambridge.

Kanbur, R. and M. Keen (1993), ôJeux Sans Frontieres: Tax Competition and Tax Coordination when Countries Differ in Sizeö, American Economic Review, Vol. 83, pp. 877-892.

Keen, M. (1987), ôWelfare Effects of Commodity Tax Harmonisationö, Journal of Public Economics, Vol. 33, pp. 107-114.

(1989), ôPareto-Improving Indirect Tax Harmonisationö, European Economic Review, Vol. 33, pp. 1-12.

Keen, M. and S. Lahiri (1993), ôDomestic Tax Reform and International Oligopolyö, Journal of Public Economics, Vol. 51, pp. 55-74.

Lahiri, S. and P. Raimondos (1997), ôPublic Good Provision and the Welfare Effects of Indirect Tax Harmonisationö, forthcoming in Journal of Public Economics.

Lockwood, B. (1996), ôCan Commodity Tax Harmonisation be Pareto-Improving when Governments Supply Public Goods?ö, forthcoming in Journal of International Economics.

Lopez-Garcia, M.A. (1996), ôThe Origin Principle and the Welfare Gains from Indirect Tax Harmonizationö, International Tax and Public Finance, Vol. 3, pp. 83-93.

Munk, K.J. (1978), ôOptimal Taxation and Pure Profitö, Scandinavian Journal of Economics, Vol. 80, pp. 1-19.

Rose, M. (1985), ôOptimal Tax Perspective on Tax Coordinationö, in S. Cnossen (ed.), Tax Coordination in the European Community, Kluwer Law and Taxation Publishers, Deventer, pp. 113-138.

Turunen-Red, A.H. and A.D. Woodland (1990), ôMultilateral Reform of Domestic Taxesö, Oxford Economic Papers, Vol. 42, pp. 160-186. 